\title{
An Investigation on Different Physical Properties of Cotton Woven Fabrics
}

\author{
Shilpi Akter \\ Asst. Professor and Head, Department of Fabric Engineering, Bangladesh University of Textiles.
}

\begin{abstract}
In this study, "An Investigation on Different Physical Properties of Cotton Woven Fabrics", some sample fabrics were produced with plain, 2/2 twill, 3/1 twill and 4-end satin weave structure using four different weft counts. By means of regression, the correlation coefficient and correlation between different properties of fabrics were investigated. The findings of this study revealed that the crease recovery angle and the bending length are inversely proportional to each other. It was also found that with the increasing of weft yarn counts lead to a decreasing in stiffness, abrasion resistance and increasing in crease recovery angle. The pilling and wrinkle recovery affected very low by the increase of weft yarn count and for the variation of weave structure. Plain weave was superior to other structures in stiffness where as twill weave showed higher crease recovery.

Keywords: Physical properties, weave structures, Woven fabric, weft count.
\end{abstract}

\section{INTRODUCTION}

Cotton is the most important raw material for woven fabrics. Cotton fibers differ remarkably from other cellu lose fibers in morphological traits and it has some advantages like good durability, chemically stable, undamaged in the continuous exposure of weak acids and alkalis. It has high waterabsorbing capacity and in a humid atmosphere, it can absorb $27 \%$ of water without getting damp [1].

Weaving is the action of producing fabrics by the interlacing of warp and weft threads. Many varieties can be produced by weaving and these fabrics are generally more durable, can be easily cut into different shapes and they are excellent for producing styles in garments. However, fabrics having more thread density (number of wrap and weft yarns present) keep the shape well. Low count fabrics are less durable and may snag or stretch. The fibre properties and the type of spinning influence the yarn properties, while the fabric properties are also influenced by the warp and weft density of the woven fabrics, and weave structure [2-4].

Bending and drape properties of woven fabrics depend on weft density, weft yarn count and warp tension. In the case of the fabrics woven with thicker weft yarns, the overall fabric rigidity increased as warp tension increased. Bending rigidity values of warp direction for sateen fabrics were higher than the values of plain fabrics and it was lower for sateen fabrics than the values of plain fabrics [5-6].

Abrasion and pilling resistance are the frictional properties of woven fabrics. Pilling is a great problem with clothes, not only impairs its appearance, but also reduces its service life. The entangled balls are from fibers sloughing off onto the fabric surface. In a tight weave the fibers will be less likely to slough off resulting in less pilling. Plain weave fabrics will be the least likely to pill, followed by twill and satin [7].

The ability of a fabric to resist wrinkling is determined by the amount of mobility the fibers and yarns have within the construction. Yarns and fibers within a plain weave construction have little freedom to move about limiting their ability to recover after deformation. A plain weave will have the least resistance to wrinkle recovery. Twill weave have the second highest recovery followed by a satin weave [8].

In this research work, some of the important physical properties of fabric were investigated. They are fabric stiffness, crease recovery, abrasion resistance, pilling resistance and wrinkle recovery properties. The properties of woven fabrics are influenced by the weaving conditions, e.g. speed of weaving, warp insertion rate, weft beat-up force, etc. The properties of raw fabrics also depend on the construction and technical parameters. To have different functional properties of an end product, raw fabrics also need to be post-treated [9].

\section{EXPERIMENTAL WORK}

\subsection{Fabric (Sample)}

For this research work, sixteen different cotton woven fabric samples were produced with various weft count and weave structures in the weaving shed of BUTEX. The details of the fabric samples were listed in table1. Weft yarns were 20's/1 $\mathrm{Ne}, 30$ 's $/ 1 \mathrm{Ne}, 40$ 's/1 $\mathrm{Ne}$ and 50's/1 Ne count yarns. Warp yarns were 20 's/1 Ne. All woven fabric samples were produced on Picanol Air Jet weaving machine with the following particulars: 
Warp yarn count

Weft yarn count

Warp density

Weft density

Fabric width

Nu mber of Harness

Frames

Weave structure

Machine speed
: 20's/1 Ne (open end)

: 20 's $/ 1 \mathrm{Ne}, 30$ 's $/ 1 \mathrm{Ne}$, 40 's/1 $\mathrm{Ne}$ and 50 's/1 Ne (open end)

: $80 /$ inch

:60/inch

$: 180 \mathrm{~cm}$.

: 8

: 1/1 plain, 2/2 Twill,

3/1 Twill, 4-end Satin : $587 \mathrm{ppm}$
Table 1. Details of the woven fabric samples.

\begin{tabular}{|c|c|c|}
\hline $\begin{array}{c}\text { Sample } \\
\text { No }\end{array}$ & $\begin{array}{c}\text { Weave } \\
\text { Structures }\end{array}$ & $\begin{array}{c}\text { Weft } \\
\text { Count(Ne) }\end{array}$ \\
\hline 1 & $1 / 1$ Plain & 20 s $/ 1$ \\
\hline 2 & $1 / 1$ Plain & 30 s $/ 1$ \\
\hline 3 & $1 / 1$ Plain & 40 s $/ 1$ \\
\hline 4 & $1 / 1$ Plain & 50 s $/ 1$ \\
\hline 5 & $2 / 2$ S Twill & 20 s $/ 1$ \\
\hline 6 & $2 / 2$ S Twill & 30 s $/ 1$ \\
\hline 7 & $2 / 2$ S Twill & 40 s $/ 1$ \\
\hline 8 & $2 / 2$ S Twill & 50 s $/ 1$ \\
\hline 9 & $3 / 1$ S Twill & 20 s $/ 1$ \\
\hline 10 & $3 / 1$ S Twill & 30 s $/ 1$ \\
\hline 11 & $3 / 1$ S Twill & 40 s $/ 1$ \\
\hline 12 & $3 / 1$ S Twill & 50 s $/ 1$ \\
\hline 13 & 4 -end Satin & 20 s $/ 1$ \\
\hline 14 & 4-end Satin & 30 s $/ 1$ \\
\hline 15 & 4-end Satin & 40 s $/ 1$ \\
\hline 16 & 4-end Satin & 50 s $/ 1$ \\
\hline
\end{tabular}

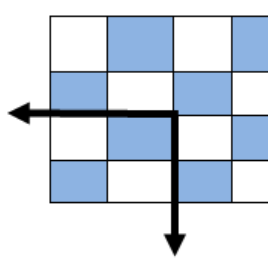

1/1 Plain

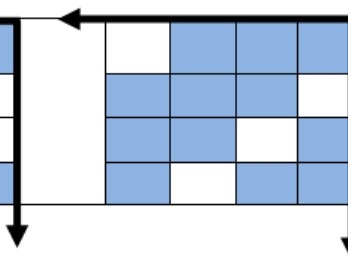

3/1Twill

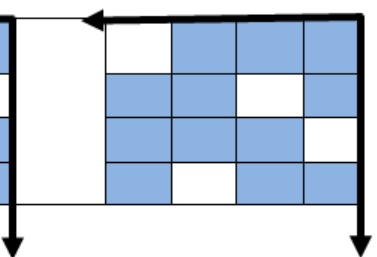

4-end Satin

Figure 1. Weave structures of woven fabrics.

\subsection{Laboratory Work}

Weave structures of the woven fabrics in this study were shown in fig. 1. All the samples were tested in the grey state of the fabric. Though the variations in all fabric samples were conducted in weft directions, all fabric properties were evaluated in both warp and weft directions to investigate any variations along the warp directions due to various weave structures. Before testing, all woven fabrics were conditioned for 24 hours in a standard atmosphere, i.e., $20{ }^{\circ} \mathrm{C} \pm 2$ temperature and $65 \% \pm 2$ Relative humidity. Ten individual readings were taken and averaged for each fabric property. The standard test methods followed for testing woven fabric properties are listed in Table 2.

Table 2. Standard test methods of the properties measured.

\begin{tabular}{|l|c|}
\hline \multicolumn{1}{|c|}{ Fabric property } & Standard Test Method \\
\hline Fabric stiffness & ASTMD 1388-9612002 \\
\hline Crease recovery & EN 22323/ ISO 2313 \\
\hline Abrasion resistance & BS 5690 \\
\hline Pilling & ISO 12945-2-2000 \\
\hline Wrinkle recovery & AATCC 128 \\
\hline
\end{tabular}

\subsection{Machine and Instruments Used}

\subsubsection{Air Jet Weaving Machine}

Computerized operated Air Jet weaving machine was manufactured by Picanol Delta X, Belgium. The fabric samples were produced in this loom.

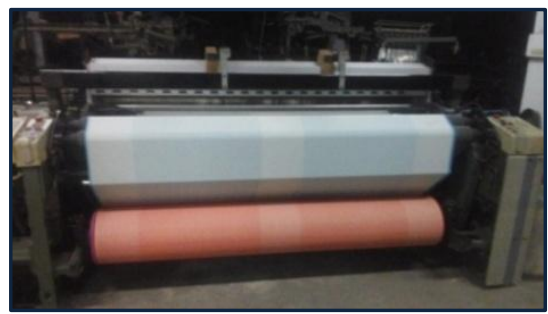

Figure 2. A ir Jet Weaving Machine.

\subsubsection{Shirley Stiffness Tester}

In this work, fabric stiffness was tested by the Shirley Stiffness Tester, brand: SDL Atlas, origin UK.

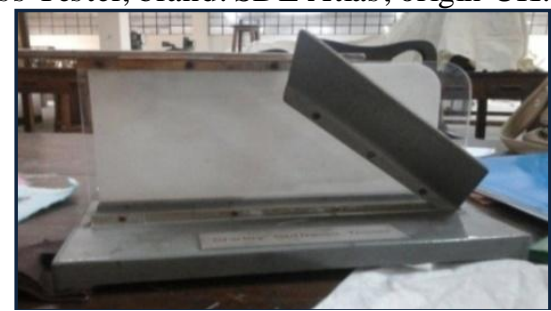

Figure 3. Shirley Stiffness Tester. 


\subsubsection{Wrinkle Recovery Tester}

Wrinkle Recovery Tester is used to assess the wrinkle mark on the fabric. Assessment is done visually compared with set of photography. Model of the mach ine 155, Brand James H. Heal, Origin U.K.

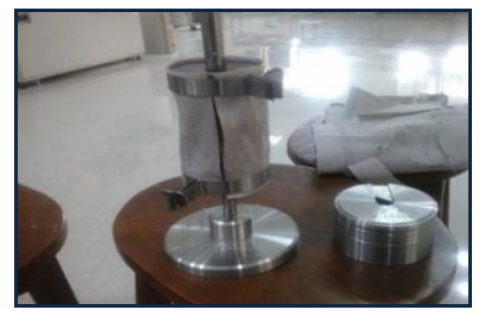

Figure 4. Wrinkle Recovery Tester.

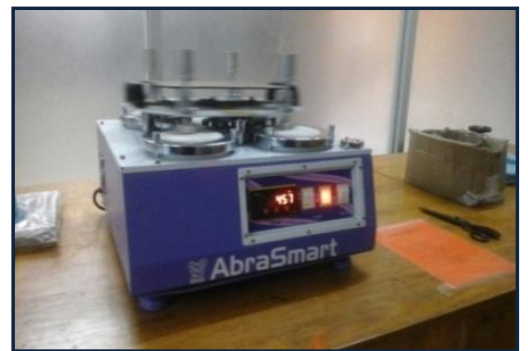

Figure 5. Martindale Abrasion Tester.

\subsubsection{Martindale Abrasion Tester for Pilling and Abrasion}

Pilling is a fabric surface fault characterized by little pills of entangled fiber clinging to the cloth surface and providing the garments an unsightly appearance. The pills are formed during wearing and washing by the entanglement of fibers which protrude from the fabric surface. The abrasion resistance of the woven fabric samples was evaluated by the percentage of fabric weight loss. The machine used was manufactured by MAC, India. The Martindale Abrasion tester was used for pilling test.

\subsubsection{The Crease Recovery Tester}

Name of the machine is Crease Recovery Angle Tester. Model 150, Brand James H. Heal and Origin U K.

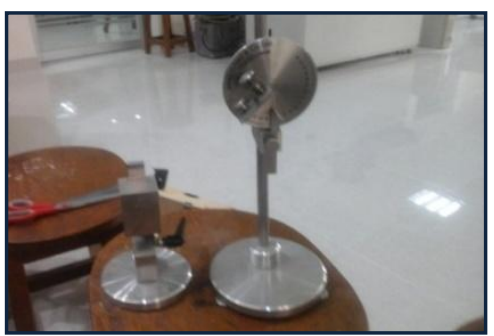

Figure 6. Crease Recovery Tester.

\section{RESULT AND DISCUSSION}

\subsection{Fabric Stiffness (Bending length)}

Stiffness is one of the most widely used parameter to measure bending rigidity, fabric handling and drape. Fabric stiffness and handling is an important factor for the end product. Fabric stiffness is related to its properties such as fiber material, yarn count, yarn sett and fabric structure. In this work, the effects of weft count and weave structure of cotton woven fabrics on fabric stiffness were investigated. The results of fabric stiffness were depicted in fig. 7 and 8.

From the fig. 7 and 8 , it is found that, bending length of plain is higher than twill and satin weave. The average decrease rate of bending length from $1 / 1$ plain to $2 / 2$ twill, $2 / 2$ twill to $3 / 1$ twill and $3 / 1$ twill to 4 -end satin are $2.4 \%, 8.5 \%$ and $6.1 \%$ respectively.

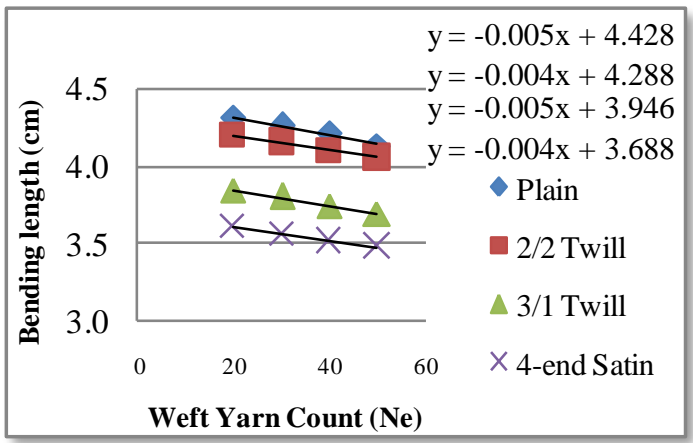

Figure 7. Trend line, re lationship equations and variation of fabric stiffness at different we ft yarn count and weave structure (warp- way).

It is found that with the increase of weft yarn count the bending length for all types of fabric structures are decreased. The average decrease rate of bending length from $1 / 1$ plain to $2 / 2$ twill, $2 / 2$ twill to $3 / 1$ twill and $3 / 1$ twill to 4 -end satin are $23.95 \%, 7.61$ $\%$ and $11 \%$ respectively.

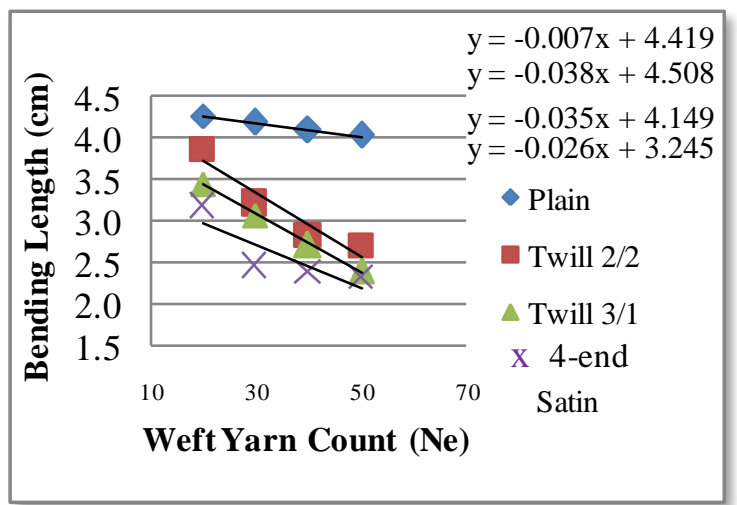

Figure 8. Trend line, relationship equations and variation of fabric stiffness at different weft yarn count and weave structure (weft-way). 
Statistical analysis showed that the stiffness of woven fabrics has been affected significantly at 0.05 average significance level by both weave structure and weft count. Weft count has a profound influence on fabric stiffness and decreasing trend was observed. It is assuring that as the weft count increases, the fabric stiffness is decreased. This is because the increase in weft count decreases the fabric tightness, which interns decreases fabric stiffness. Increasing weft count from 20 's/1 to 50 's/1 $\mathrm{Ne}$ leads to a decreasing of fabric stiffness for Plain, 2/2 Twill, 3/1 Twill and Satin respectively. From the fig. 7 and 8 , it is also found that the stiffness of woven fabrics of plain weave is higher than the other forms of structures. The higher stiffness of plain weave can be assigned to the higher tightness of fabrics.

\subsection{Fabric Crease Recovery}

The crease recovery is one of the elementary properties of fabrics which affect product performance. Crease recovery is the ability of the fabric to return to its original shape after removing the folding deformations. The crease recovery of fabrics is determined by measuring the crease recovery angle. As the crease recovery angle increases the fabric crease recovery increases.

It is found from the fig. 9 and 10 , that there are fewer differences of crease recovery angles due to the different weave structure. It is also found that, due to the increase of the weft yearn count, the crease recovery angle also increases for all types of weave structures. From fig. 9, satin weave shows higher recovery angle than twill and plain weaves and from fig. 10, twill weave exhibits higher crease recovery angle than plain and satin.

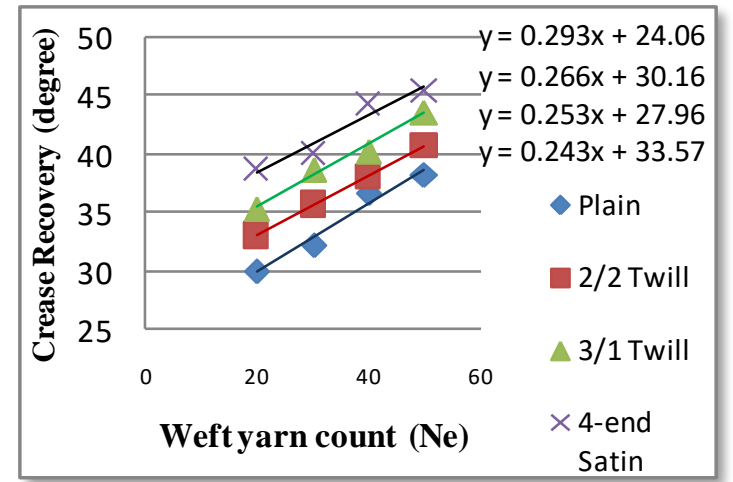

Figure 9. Trend line, relationship equations and variation of crease recovery angles at different weft yarn count and weave structure (warp-way).

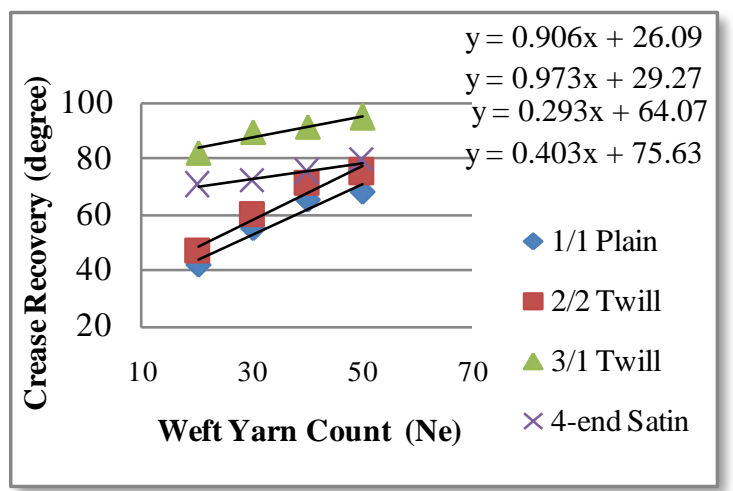

Figure 10. Trend line, relationship equations and variation of crease recovery angles at different weft yarn count and weave structure (weft-way).

From the fig., it is found that both variables, i.e. weave structure and weft count have a significant effect on fabric crease recovery. An increased trend is observed in both directions. In the warp and weftway, crease angle is increased for plain, twill and satin structure respectively. It is also shown that twill fabric exhibited higher crease recovery followed by satin and plain weaves respectively.

\subsection{Fabric Wrinkle Recovery}

The wrinkle recovery is another important property of woven fabric. Wrinkle is an unwanted short and irregular crease in a fabric. The difference between a wrinkle and a crease is creases are generally sharper and longer than wrinkles. Wrinkle resistance is recovery from creasing of a textile material during use. In this experiment, the grading was done visually with the help of standard grade sheet photography. From the above fig., it is found that there is no remarkable change of wrinkle recovery with the increase of weft yarn count and it is better for twill and satin over plain weave.

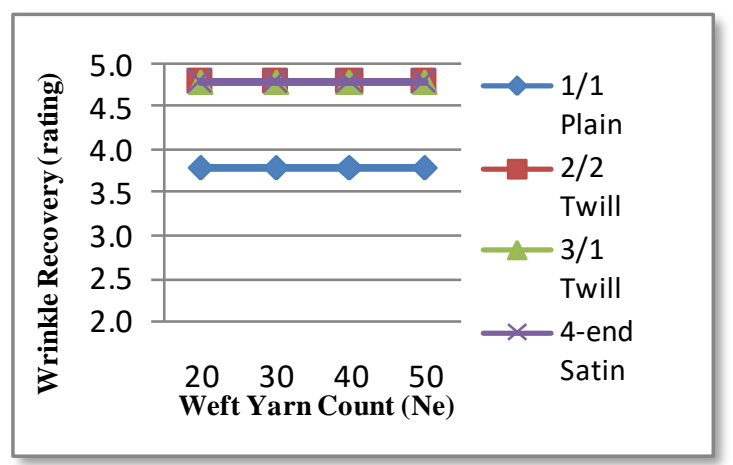

Figure 11. Variation of wrinkle recovery of different samples.

In this study, it is found that, for the variation in the weft count and weave structure; there are no significant differences for wrinkle recovery. 
All the grading were 3.8 and 4.8 , which means the wrinkle recovery is moderate good.

\subsection{Fabric Abrasion resistance}

In this study, the abrasion resistance of the woven fabric samples was evaluated by the percentage of fabric weight loss. As the weight loss decreases, the abrasion resistance of the woven fabrics increases. The weight loss of the woven fabric sample according to weave structure type and weft yarn count was plotted in figure 12. The statistical analysis showed the huge influence of the weft count and weave type on the weight loss of woven fabrics. It is found from the Figure 12 that with the increase of weft yarn count the weight loss percentage of all types of fabric structure decreases. This is because due to the increase of weft count. Weight loss percentage is higher for satin weave than twill and plain. The plain weave is having better abrasion resistance than twill and satin weave.

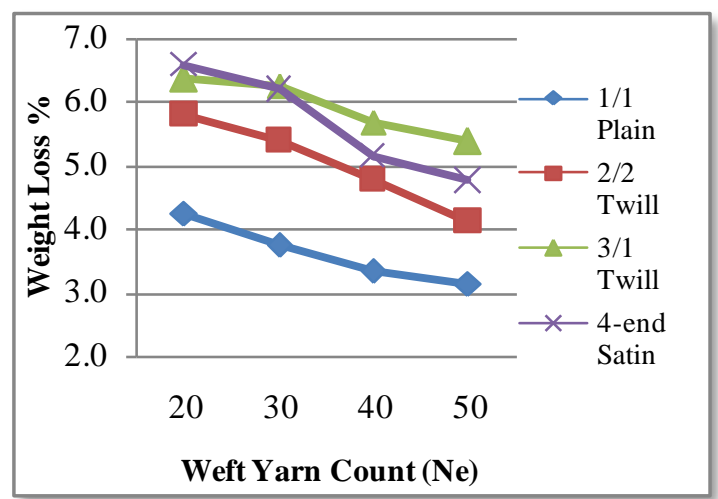

Figure 12. Variation of fabric weight loss $\%$ at different levels of weft count and weave structure for 2000 cycle.

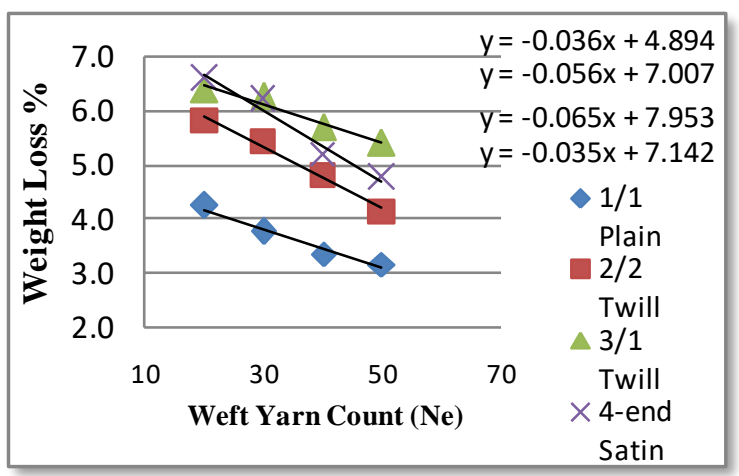

Figure 13. Trend line and relationship equations between weft yarn count and weight loss \%.

\subsection{Fabric Pilling Resistance}

Table 3. Pilling resistance rating of different samples for 2000 cycles.

\begin{tabular}{|c|c|c|c|}
\hline Samples & Pilling Rating & Comments & Fabric Quality \\
\hline Plain & 4 & Slight Pilling & Very Good \\
\hline 2/2 Twill & $3-4$ & Moderate Pilling & Good \\
\hline 3/1 Twill & $3-4$ & Moderate Pilling & Good \\
\hline 4-end Satin & $3-4$ & Moderate Pilling & Good \\
\hline
\end{tabular}

The pilling property is a very important factor in the performance of some textile materials. In this study, the fabric samples were rubbed for 2000 cycles and the amount of pills formed on the surface of the fabrics were assessed visually compared with supplied standard photography. It is found that plain structure exhibits a less number of pilling other than twill and satin structure. In this case, no significant differences were found for we ft count variation. From the table 3, it can be said that pilling resistance is superior for plain than other weave structures.

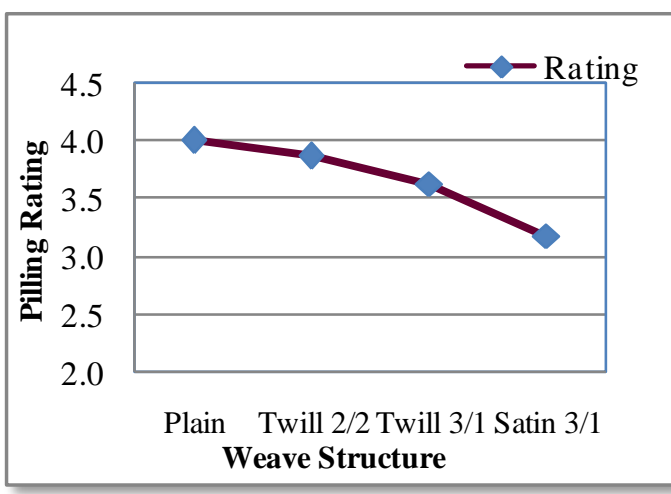

Figure 14. Variation of pilling resistance of different samples for 2000 cycles.

From the fig. 14, it can be said that pilling resistance is gradually decreases from plain to twill and satin structure. 
3.6 Correlation Analysis of Different Properties for Selected Woven Fabrics

3.6.1 Correlation analysis between crease recovery angle and bending length in the warp and weftway direction.

In order to find the correlation between the crease recovery angle and bending length, the $\mathrm{R}$ square of each relation was considered to see whether the relation obtained was positive or negative.

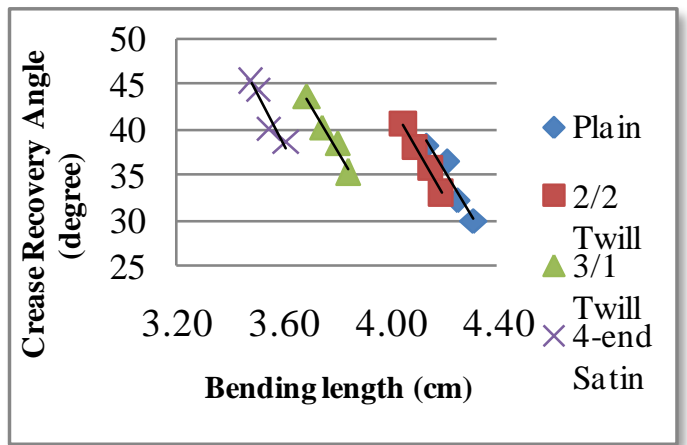

Figure 15. Crease recovery angle versus bending length for various weave structure (warp-way).

From the above fig. 15 and 16, it can be said that crease recovery angle and bending length in both direction having a strong inverse relationship. Among 4 samples, twill having a strongest opposite relationship followed by plain and 4-end satin. As the crease recovery angle increases in a woven fabric, the bending length will decrease. Crease recovery angle and bending length are inversely proportionate to each other.

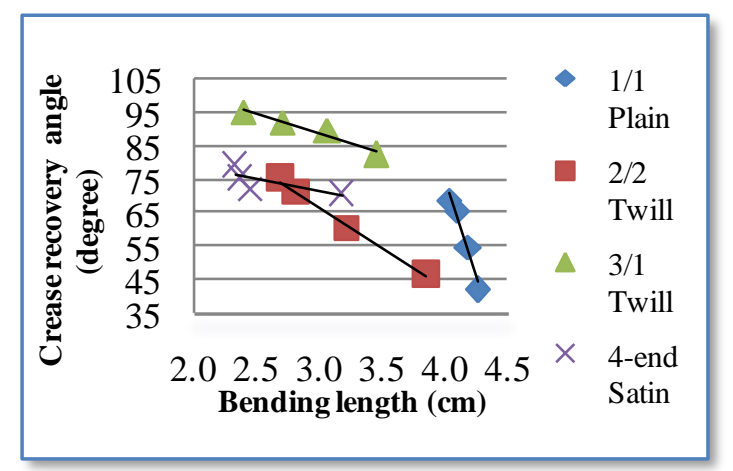

Figure 16. Crease recovery angle versus bending length for various weave structure in the weftdirection.

\section{CONCLUSION}

In this research work, all samples were tested in the gray state of the fabrics. Therefore, there might be some influence of sizing materials on the different fabric properties. Various physical properties of cotton woven fabrics of different weave structures were investigated. The correlation between various properties of woven fabrics with different weft count and weave structure were investigated. The results of the research can be summarized as follows:

The increase in weft count leads to a decrease in fabric stiffness. Plain fabric showed higher fabric stiffness than twill and satin weave.

As the weft count increases, the crease recovery angle also increases. Twill fabric exhibited higher crease recovery other than satin and plain respectively.

It was found that as the weight loss decreases with the increases of weft count, the abrasion resistance of the woven fabric increases.

The pilling and wrinkle recovery were slightly affected by the increase of weft count and weave structure. Plain weave shows better performance means better grading followed by twill and satin. Crease recovery angle and bending length are inversely proportionate to each other.

\section{REFERENCES}

[1]. http://xmtextiles.com/en/component/virtuemart /cotton-fabric/cotton-fabric-propertiesdetail.html. Accessed on 28 November 2015.

[2]. http://en.wikipedia.org/wiki/Woven_fabric. Accessed on 16 November 2015.

[3]. http://www.textiles chool.com/articles/375/ woven-fabrics\#s thash.YI7oygnW.dpuf.

Accessed on 11 December 2015.

[4]. Edited by Prof. Dr. P. D. Dubrovsk, (2010). Woven Fabric Engineering (Sciyo Janeza Trdine. Croatia. ISBN 978-953-307-194-7).

[5]. Süle, Gülcan, Investigation of Bending and Drape Properties of Woven Fabrics and the Effects of Fabric Constructional Parameters and Warp Tension on These Properties, Textile Research Journal, 0(00) 1-10, DOI: 10.1177/ 0040517511433152, 1 December 2012.

[6]. Lawal, A.S., Bawa, I., Nkeonye, Analysis of the Properties of Plain Woven Fabrics Produced from Flax/Cotton Blend, International Journal of Science and Research (IJSR), ISSN (Online): 2319-7064.

[7]. Joseph O. Ajayi1, Effects of Fabric Structure on Frictional Properties, Textile Research Journal . vol. 62 no. 2 87-93, February 1992.

[8]. http://www.scribd.com/doc/ 29696779/Effectof-Weaves-on-the-Fabric-Property \#scribd. Accessed on 29 December 2015.

[9]. Edited by Prof. Dr. P. D. Dubrovsk, Woven Fabric Engineering (Sciyo Janeza Trdine. Croatia. ISBN 978-953-307-194-7, 2010). 